\title{
Risk of liver cancer among US male veterans with cirrhosis, 1969-1996
}

\author{
EC Persson*,', SM Quraishi', TM Welzel'2, JD Carreon', G Gridley', BI Graubard' and KA McGlynn' \\ 'Division of Cancer Epidemiology and Genetics, National Cancer Institute, National Institutes of Health, Department of Health and Human Services, \\ Bethesda, MD 20852-7234 USA; ${ }^{2}$ Klinikum der JW Goethe-Universität Frankfurt am Main, Medizinische Klinik I, Theodor-Stern-Kai 7, 60590 Frankfurt \\ am Main, Germany
}

BACKGROUND: Liver cancer incidence rates in the United States have increased for several decades for reasons that are not entirely clear. Regardless of aetiology, cirrhosis is a strong risk factor for liver cancer. As mortality from cirrhosis has been declining in recent decades, it is possible that the risk of liver cancer among persons with cirrhosis has been affected.

METHODS: Data from the US Veterans Affairs medical records database were analysed after adjustment for attained age, race, number of hospital visits, obesity, diabetes, and chronic obstructive pulmonary disease. Hazard ratio (HR) and 95\% confidence interval (95\% $\mathrm{Cl}$ ) were calculated using Cox proportional hazards modelling. Survival analyses were conducted using age as the time metric and incidence of cirrhosis as a time-dependent covariate.

RESULTS: Among 103257 men with incident cirrhosis, 788 liver cancers developed. The HR of liver cancer was highest among men with viral-related cirrhosis ( $\mathrm{HR}=37.59,95 \% \mathrm{Cl}$ : 22.57-62.6I), lowest among men with alcohol-related cirrhosis ( $\mathrm{HR}=8.20,95 \% \mathrm{Cl}$ : 7.55-8.9 I) and intermediate among men with idiopathic cirrhosis $(H R=10.45,95 \% \mathrm{Cl}: 8.52-12.81)$, when compared with those without cirrhosis. Regardless of cirrhosis type, white men had higher HRs than black men. The HR of developing liver cancer increased from 6.40 (95\% Cl: 4.40-9.33) in 1969-1973 to 34.7I (95\% Cl: 23.10-52.16) in 1992-1996 for those with cirrhosis compared with those without. CONCLUSION: In conclusion, the significantly increased HR of developing liver cancer among men with cirrhosis compared with men without cirrhosis in the United States may be contributing to the increasing incidence of liver cancer.

British Journal of Cancer (2012) 107, 195-200. doi: I0.1038/bjc.2012.193 www.bjcancer.com

Published online 15 May 2012

(C) 2012 Cancer Research UK

Keywords: liver cancer; cirrhosis; epidemiology; cohort; US Veterans Affairs

Incidence rates of primary liver cancer in the United States have been increasing since 1980 (Altekruse et al, 2009). In the United States, known risk factors for liver cancer, the majority of which is hepatocellular carcinoma (HCC), include chronic infection with hepatitis $B$ virus (HBV), chronic infection with hepatitis $C$ virus (HCV) (Davila et al, 2004; Davila et al, 2011) and excessive alcohol consumption (Bosetti et al, 2007). In addition, recent research has identified pre-existing diabetes (El-Serag et al, 2004), obesity (Neuschwander-Tetri and Caldwell, 2003) and metabolic syndrome (Welzel et al, 2011) as risk factors. Although changes in epidemiological patterns of risk factors may have influenced liver cancer incidence trends, other factors may also have contributed to the rising rates. For example, regardless of risk factor, $70-90 \%$ of liver cancers arise in livers that are affected with pre-existing cirrhosis (Schutte et al, 2009). In the United States, mortality due to cirrhosis has been declining since the early 1970s (National Center for Health Statistics (US), 2010) as treatment has improved (Kanwal et al, 2011). As cirrhosis and liver cancer are closely associated, the inverse trends in liver cancer incidence and cirrhosis mortality suggest that the two phenomena may be related. It is conceivable that as persons with cirrhosis are treated more successfully, the risk of developing liver cancer may be

*Correspondence: Dr EC Persson, E-mail: christina.persson@nih.gov Received 3 January 2012; revised 12 April 2012; accepted 14 April 2012; published online 15 May 2012 affected. To investigate this hypothesis, the relationship between liver cancer and cirrhosis was examined in a large cohort of US military veterans.

\section{MATERIALS AND METHODS}

\section{Study cohort}

The study utilised hospital discharge diagnoses that occurred between 1 July, 1969 and 30 September, 1996 at 142 US Veterans Affairs (VA) hospitals. This inpatient-only study population included all black $(N=816395)$ and white $(N=3599650)$ male veterans between the ages of 18 and 100 years who were hospitalised at least once during the study period. Men belonging to ethnic/racial groups other than black or white were excluded from the study because of small numbers. Females were also excluded because of small numbers. Almost 26 million hospital discharge records were included. Hospital discharge diagnoses from 5790493 male veterans were identified. Persons were excluded $(N=917867)$ for a number of reasons: non-veterans, age $<18$ years or $>100$ years, died at the first hospital admission, developed cancer during the first year of study entry or had prevalent cancer on first admission. In addition, 371129 men were excluded because of failure to survive 1 year after diagnosis and 85452 men were excluded who had a diagnosis of cirrhosis before or at the day of entry. In total, hospital discharge diagnoses of 4416045 male 
veterans who accumulated 51574455 person-years of follow-up were examined.

All diagnoses of the following conditions were noted: cirrhosis, HBV, HCV, alcohol-related conditions, obesity, diabetes and chronic obstructive pulmonary disease (COPD; for use as a proxy variable for heavy smoking). To estimate the risk of liver cancer, the cohort was followed until the first of the following events occurred: first liver cancer diagnosis, death, or end of observation period (30 September, 1996). Dates of death were ascertained by linkage to the Social Security Administration mortality files. A diagnosis of HCC was identified using International Classification of Diseases (ICD), versions 8A or 9CM code 155 . The cirrhosis codes selected in ICD-8A and ICD-9CM were 571.0, 571.8, and 571.9 (v.8A), and 571.2, 571.5, and 571.6 (v.9CM). Alcoholic liver cirrhosis codes selected were 571.0 (ICD-8A) and 571.2 (ICD-9CM). The viral hepatitis codes in ICD-8A and ICD-9CM are dissimilar in that ICD-8A does not distinguish between HBV and HCV, whereas ICD-9CM does make the distinction. For the purpose of the current study, all viral hepatitis was incorporated into a single category (ICD-8A; 070 plus either 571.8 or 571.9 and ICD-9CM: 070.2, 070.3, $070.4,070.5,070.7,571.5)$. Idiopathic cirrhosis was defined by having a cirrhosis code, excluding both alcoholic cirrhosis and viral hepatitis. Obesity was identified by the codes ICD-8A 277 and ICD-9CM 278.0, and diabetes was identified by the sole diabetes code in both ICD-8A and ICD-9CM 250. COPD (without asthma) was identified to serve as a proxy variable for cigarette smoking (ICD-8A 490-492 and ICD-9CM 490-492, 494-496). The study was approved by the NIH Office of Human Subjects Research.

\section{Statistical analysis}

The number of person-years of follow-up began after the first hospital discharge and ended at the date of first discharge diagnosis of liver cancer, date of admission to hospital with liver cancer diagnosis, date of death, or date at end of the study period (30 September, 1996), whichever came first. Men diagnosed with cirrhosis at entry were excluded. Records were linked to Social Security Administration Death Master File records to determine dates of death (Page et al, 1996).

Crude analyses consisting of age-adjusted incidence rates for liver cancer were calculated in 5-year calendar periods 1969-1973, 1974-1979, 1980-1985, 1986-1991 and 1992-1996, comparing men with cirrhosis and men without cirrhosis. In multiple variable analyses, HR and 95\% confidence intervals (95\% CI) adjusted for race, number of hospital admissions, obesity, diabetes, and COPD were calculated using Cox proportional hazards modelling. Survival analysis was conducted using age as the time metric and incidence of cirrhosis as a time-dependent covariate, with the other covariates assessed at baseline as non-time dependent and conducted stratified by race and by 5 -year calendar period and by type of liver cirrhosis (related to: alcohol, hepatitis or idiopathic). For both the crude and adjusted analyses, because cirrhosis was a time-dependent covariate for 5-year time period stratified and unstratified analyses, individuals with prevalent cirrhosis at the beginning of the time period were excluded from incidence analysis of liver cancer.

Interaction with race was tested for each cirrhosis variable. Weighted least squares analysis was used to test trend in the estimated HRs across 5-year calendar time periods. All analyses were run using SAS software (version 9.1.3) and SAS-callable SUDAAN 10.0 functions (SAS Institute, Cary, NC, USA).

\section{RESULTS}

\section{Characteristics of study population}

The study included 4416045 study participants, of whom 103257 were diagnosed with cirrhosis after at least one cirrhosis-free hospitalisation (Table 1). The most common type of cirrhosis was alcoholic cirrhosis $(N=92208)$, followed by viral hepatitis-related cirrhosis $(N=779)$. The remaining cirrhosis diagnoses (idiopathic cirrhosis) were unrelated to either alcohol or viral hepatitis $(N=10270)$. Among the 103257 men who were diagnosed with cirrhosis, 788 subsequently developed liver cancer during followup (Table 2). In contrast, of the 4312788 men without cirrhosis, 3620 subsequently developed liver cancer. The mean follow-up time among men with cirrhosis was 9.8 years among white men and 11.2 years among black men. In men with cirrhosis who developed liver cancer, the mean length of follow-up was 6.8 years for white men and 7.7 years for black men (data not shown).

Table I Characteristics of the study population, US Veterans Affairs inpatient hospitalisation database, 1969-1996

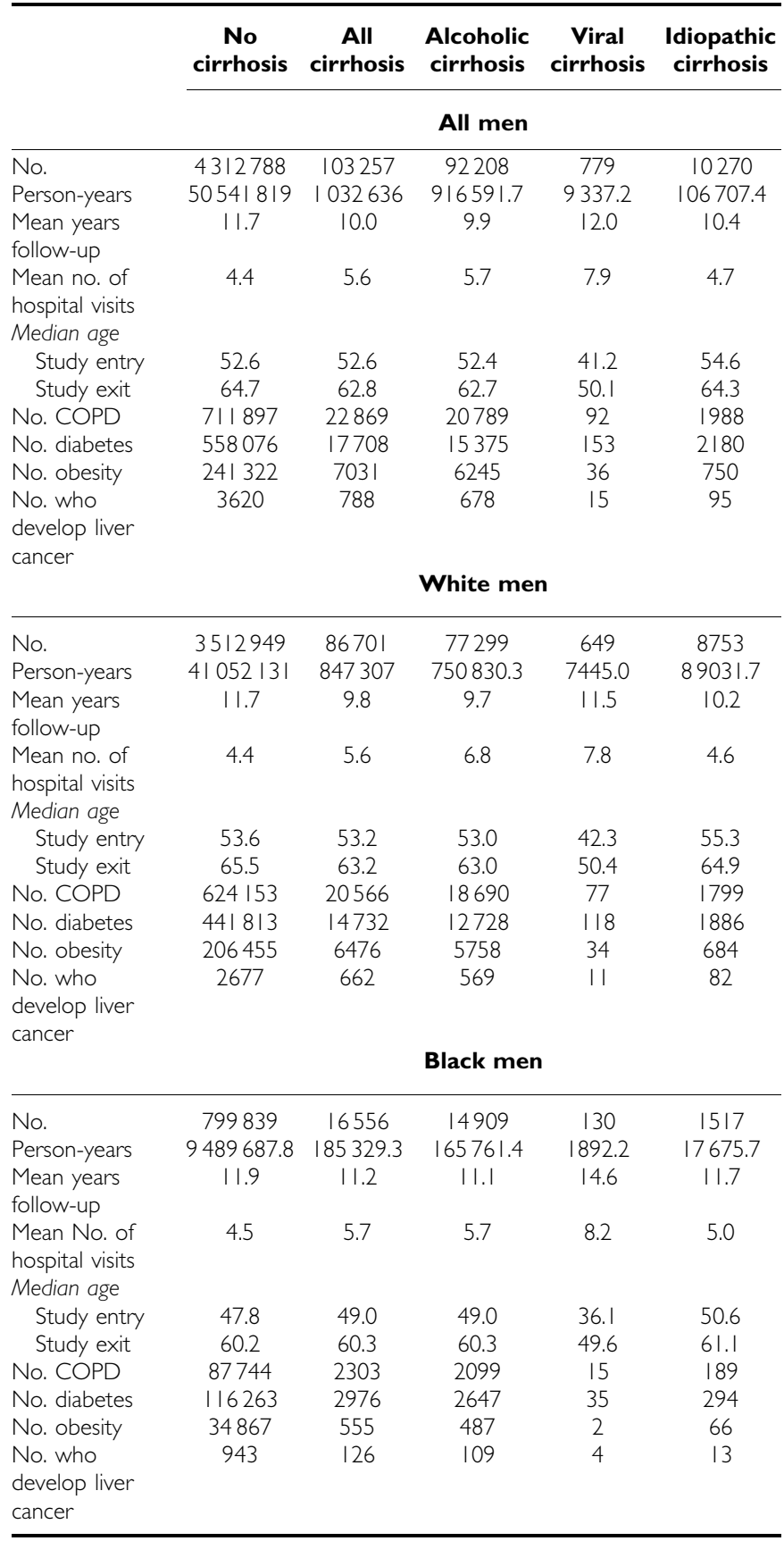

Abbreviation: COPD = chronic obstructive pulmonary disease. 
Table 2 Hazard ratio (HR) of liver cancer among US male veterans by cirrhosis status and race

\begin{tabular}{|c|c|c|c|c|c|c|c|c|c|c|}
\hline & \multicolumn{3}{|c|}{ All male veterans } & \multicolumn{3}{|c|}{ White male veterans } & \multicolumn{3}{|c|}{ Black male veterans } & \multirow[b]{2}{*}{$P$-value } \\
\hline & $\begin{array}{l}\text { No liver } \\
\text { cancer }\end{array}$ & $\begin{array}{l}\text { Liver } \\
\text { cancer }\end{array}$ & $\begin{array}{c}\mathbf{H R}^{\mathbf{a}} \\
(95 \% \mathrm{Cl})\end{array}$ & $\begin{array}{l}\text { No liver } \\
\text { cancer }\end{array}$ & $\begin{array}{l}\text { Liver } \\
\text { cancer }\end{array}$ & $\begin{array}{c}\mathbf{H R}^{\mathbf{a}} \\
(95 \% \mathrm{Cl})\end{array}$ & $\begin{array}{l}\text { No liver } \\
\text { cancer }\end{array}$ & $\begin{array}{l}\text { Liver } \\
\text { cancer }\end{array}$ & $\begin{array}{c}\mathbf{H R}^{\mathbf{a}} \\
(95 \% \mathrm{Cl})\end{array}$ & \\
\hline $\begin{array}{l}\text { No Cirrhosis } \\
\text { Cirrhosis } \\
\text { Alcoholic cirrhosis } \\
\text { Viral hepatitis- } \\
\text { related cirrhosis } \\
\text { Idiopathic cirrhosis }\end{array}$ & $\begin{array}{c}4309168 \\
102469 \\
91530 \\
764\end{array}$ & $\begin{array}{c}3620 \\
788 \\
678 \\
15\end{array}$ & $\begin{array}{c}1.00 \\
8.55(7.92-9.24) \\
8.20(7.55-8.91) \\
37.59(22.57-62.61)\end{array}$ & $\begin{array}{c}3510272 \\
86039 \\
76730 \\
638\end{array}$ & $\begin{array}{c}2677 \\
662 \\
569 \\
11\end{array}$ & $\begin{array}{c}1.00 \\
9.53(8.75-10.38) \\
9.15(8.36-10.03) \\
40.68(22.61-73.21)\end{array}$ & $\begin{array}{c}798896 \\
16430 \\
14800 \\
126\end{array}$ & $\begin{array}{c}943 \\
126 \\
109 \\
4\end{array}$ & $\begin{array}{c}1.00 \\
5.44(4.52-6.56) \\
5.19(4.25-6.34) \\
32.15(11.69-88.47)\end{array}$ & $\begin{array}{c}<0.000 \mid \\
<0.000 \text { I } \\
0.77\end{array}$ \\
\hline
\end{tabular}

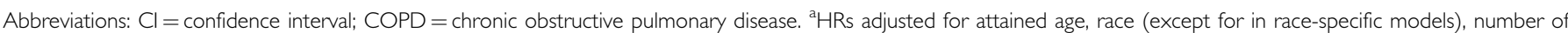
hospital visits, obesity, diabetes, COPD, and individuals with prevalent cirrhosis were removed. 'Interaction between race (white or black) and cirrhosis (yes or no).

Table 3 Hazard ratio (HR) of liver cancer among US male veterans by cirrhosis status and calendar year

\begin{tabular}{|c|c|c|c|c|c|c|c|c|c|c|c|c|c|c|c|}
\hline & \multicolumn{3}{|c|}{$1969-1973$} & \multicolumn{3}{|c|}{$1974-1979$} & \multicolumn{3}{|c|}{$1980-1985$} & \multicolumn{3}{|c|}{$|986-199|$} & \multicolumn{3}{|c|}{$1992-1996$} \\
\hline & $\begin{array}{l}\text { No liver } \\
\text { cancer }\end{array}$ & $\begin{array}{l}\text { Liver } \\
\text { cancer }\end{array}$ & $\begin{array}{c}\mathbf{H R}^{\mathrm{a}} \\
(95 \% \mathrm{Cl})\end{array}$ & $\begin{array}{l}\text { No liver } \\
\text { cancer }\end{array}$ & $\begin{array}{l}\text { Liver } \\
\text { cancer }\end{array}$ & $\begin{array}{c}\mathbf{H R}^{\mathbf{a}} \\
(95 \% \mathrm{Cl})\end{array}$ & $\begin{array}{l}\text { No liver } \\
\text { cancer }\end{array}$ & $\begin{array}{l}\text { Liver } \\
\text { cancer }\end{array}$ & $\begin{array}{c}H_{R^{a}} \\
(95 \% \text { CI) }\end{array}$ & $\begin{array}{l}\text { No liver } \\
\text { cancer }\end{array}$ & $\begin{array}{l}\text { Liver } \\
\text { cancer }\end{array}$ & $\begin{array}{c}H_{R^{a}} \\
(95 \% \text { CI })\end{array}$ & $\begin{array}{l}\text { No liver } \\
\text { cancer }\end{array}$ & $\begin{array}{l}\text { Liver } \\
\text { cancer }\end{array}$ & $\begin{array}{c}\text { HR }^{\mathbf{a}} \\
(95 \% \mathrm{Cl})\end{array}$ \\
\hline $\begin{array}{l}\text { No Cirrhosis } \\
\text { Cirrhosis }\end{array}$ & $\begin{array}{l}\mid 087293 \\
40107\end{array}$ & $\begin{array}{c}123 \\
39\end{array}$ & $\begin{array}{c}1.00 \\
6.40 \\
(4.40-9.33)\end{array}$ & $\begin{array}{c}2191055 \\
28651\end{array}$ & $\begin{array}{c}452 \\
43\end{array}$ & $\begin{array}{c}1.00 \\
8.86 \\
(6.47-12.14)\end{array}$ & $\begin{array}{c}2769524 \\
10220\end{array}$ & $\begin{array}{c}892 \\
37\end{array}$ & $\begin{array}{c}1.00 \\
15.72 \\
(11.30-21.86)\end{array}$ & $\begin{array}{c}3067938 \\
7013\end{array}$ & $\begin{array}{l}1169 \\
28\end{array}$ & $\begin{array}{c}1.00 \\
15.81 \\
(10.86-23.03)\end{array}$ & $\begin{array}{c}3023636 \\
3841\end{array}$ & $\begin{array}{c}984 \\
24\end{array}$ & $\begin{array}{c}1.00 \\
34.71 \\
(23.10-52.16)\end{array}$ \\
\hline \multirow{3}{*}{$\begin{array}{l}\text { Alcoholic } \\
\text { cirrhosis } \\
\text { Viral hepatitis } \\
\text { related-cirrhosis } \\
\text { Idiopathic } \\
\text { cirrhosis }\end{array}$} & $36|3|$ & 37 & $\begin{array}{c}6.92 \\
(4.70-10.19)\end{array}$ & 25791 & 37 & $\begin{array}{c}8.42 \\
(6.01-11.80)\end{array}$ & 8990 & 26 & $\begin{array}{c}12.78 \\
(8.65-18.88)\end{array}$ & 6061 & 22 & $\begin{array}{c}14.77 \\
(9.68-22.54)\end{array}$ & 3189 & 18 & $\begin{array}{c}32.49 \\
(20.35-51.86)\end{array}$ \\
\hline & 204 & 0 & NA & 174 & 0 & NA & 56 & 1 & $\begin{array}{c}91.52 \\
(12.30-681.16)\end{array}$ & 69 & 2 & NA & 162 & 2 & $\begin{array}{c}80.79 \\
(21.10-309.30)\end{array}$ \\
\hline & 3772 & 2 & $\begin{array}{c}2.73 \\
(0.68-11.03)\end{array}$ & 2686 & 6 & $\begin{array}{c}13.34 \\
(5.96-29.85)\end{array}$ & 1174 & 10 & $\begin{array}{c}32.35 \\
(17.34-60.36)\end{array}$ & 883 & 4 & $\begin{array}{c}15.14 \\
(5.66-40.46)\end{array}$ & 490 & 4 & $\begin{array}{c}34.88 \\
(13.07-93.12)\end{array}$ \\
\hline
\end{tabular}

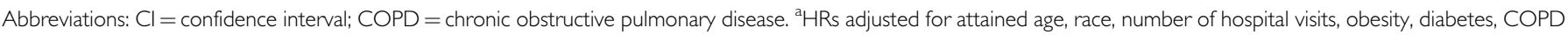
and for each 5-year time period individuals with prevalent cirrhosis removed from the analysis.

Among all cohort participants, black men entered the study cohort at younger ages (median age 47.8 ) than white men (53.6 years), and were younger at liver cancer diagnosis (black men 63.6-years-old $v s$ white men 65.9-years-old, data not shown).

\section{HRs of liver cancer by cirrhosis status and race}

Comparing men with cirrhosis to men without cirrhosis, adjusted for attained age, race, number of hospital admissions, obesity, diabetes, and COPD at baseline, the HR for liver cancer over the entire study period was 8.55 (95\% CI: 7.92-9.24) (Table 2). The HRs, however, varied by the type of cirrhosis. Men with viral hepatitis-related cirrhosis had the highest HR of liver cancer $(\mathrm{HR}=37.59,95 \% \mathrm{CI}: 22.57-62.61)$, whereas those with alcoholrelated cirrhosis (HR $=8.20,95 \%$ CI: 7.55-8.91) had the lowest HR. The HRs among men with idiopathic cirrhosis $(\mathrm{HR}=10.45,95 \%$ CI: 8.52-12.81) was intermediate to the other two when compared with men without cirrhosis. When examining each racial group separately, the findings by type of cirrhosis were consistent, with the highest $\mathrm{HR}$ in each group related to viral hepatitis-related cirrhosis and the lowest HR related to alcoholic cirrhosis. A comparison of the HRs between white and black men found that HRs were significantly higher among white men for all types of cirrhosis (white: $\mathrm{HR}=9.53,95 \%$ CI: 8.75-10.38; black: $\mathrm{HR}=5.44$, 95\% CI: 4.52-6.56), alcohol-related cirrhosis (white: $\mathrm{HR}=9.15$, 95\% CI: 8.36-10.03; black: $\mathrm{HR}=5.19, \quad 95 \%$ CI: 4.25-6.34) and idiopathic cirrhosis (white: $\mathrm{HR}=11.51,95 \% \mathrm{CI}$ : 9.24-14.35; black: $\mathrm{HR}=6.39,95 \% \mathrm{CI}: 3.70-11.05)$. Although white men with viral hepatitis-related cirrhosis $(\mathrm{HR}=40.68,95 \% \mathrm{CI}: 22.61-73.21)$ also had higher HRs than black men $(\mathrm{HR}=32.15,95 \% \mathrm{CI}$ : 11.69-88.47), the difference was not statistically significant $\left(P_{\text {interaction }}=0.77\right)$.

\section{HR of liver cancer within calendar year by cirrhosis status}

The results of the survival analysis by calendar year, in which cirrhosis was treated as a time-dependent variable, are displayed in
Table 3 . The analysis revealed a statistically significant increase $\left(P_{\text {trend }}=0.016\right)$ in liver cancer HRs for veterans with cirrhosis compared with veterans without any cirrhosis over time: 1969-1973: $\mathrm{HR}=6.40$ (95\% CI: 4.40-9.33); 1974-1979: $\mathrm{HR}=8.86$ (95\% CI: 6.47-12.14); 1980-1985: HR $=15.72 \quad(95 \% \quad$ CI: 11.30-21.86); 1986-1991: $\mathrm{HR}=15.81$ (95\% CI: 10.86-23.03) and 1992-1996: $\mathrm{HR}=34.71$ (95\% CI: 23.10-52.16). An examination of alcohol-related cirrhosis alone found very similar results $\left(P_{\text {trend }}=0.011\right)$ for: $1969-1973: \mathrm{HR}=6.92$ (95\% CI: $\left.4.70-10.19\right)$; 1974-1979: $\mathrm{HR}=8.42$ (95\% CI: 6.01-11.80); 1980-1985: HR $=12.78$ (95\% CI: 8.65-18.88); 1986-1991: HR = 14.77 (95\% CI: 9.68-22.54) and 1992-1996: HR $=32.49$ (95\% CI: 20.35-51.86). The numbers of liver cancers associated with other types of cirrhosis were too small for calculation of the HRs by time period.

\section{Liver cancer incidence rate between 1969 and 1996}

Overall, the incidence rate of liver cancer increased from 1969 to 1996 , from 8.1 out of 100000 to 9.1 out of 100000 person-years. Among white men, the incidence increased from 7.6 in 1969 to 8.5 out of 100000 person-years in 1996, whereas among black men the incidence increased from 10.3 in 1969 to 11.5 out of 100000 person-years in 1996 (data not shown). Further, the incidence rate of liver cancer among men with and without cirrhosis shown in Figure 1 is analogous to Table 3 over time. Between 1969 and 1996 the incidence of liver cancer among men with cirrhosis increased from 36.1 to 247.3 out of 100000 person-years, whereas the incidence among men without cirrhosis only slightly increased from 6.5 to 7.9 out of 100000 person-years. The incidence of liver cancer by race in men with cirrhosis increased from 31.5 to 256.0 out of 100000 person-years among white men, and from 56.9 to 180.0 out of 100000 person-years among black men. Among men without cirrhosis, a slightly increased incidence was evident among both white (from 6.2 in 1969 to 7.3 out of 100000 person-years in 1996) and black men (from 7.6 to 10.6 out of 100000 person-years, data not shown). 


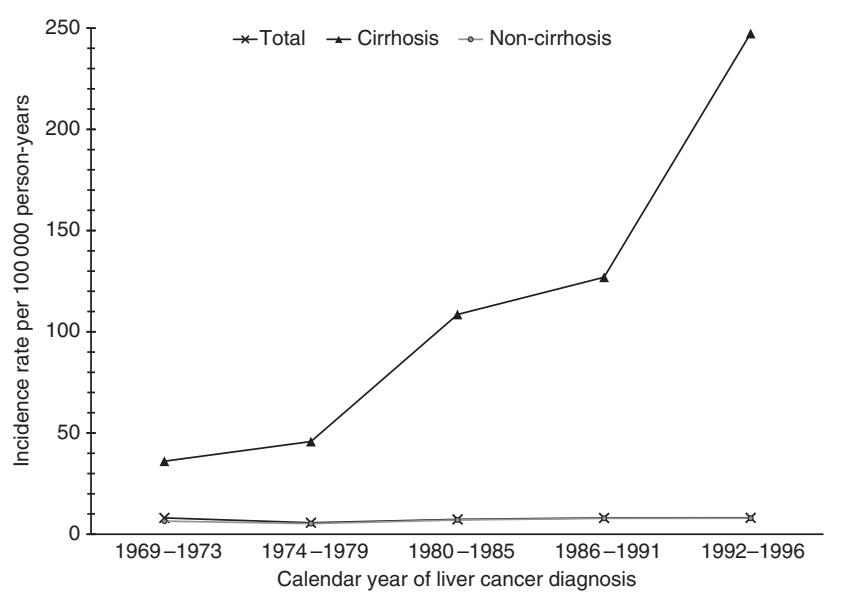

Figure I Incidence of liver cancer by cirrhosis status, VA 1969-1996. Age-adjusted incidence rates of liver cancer by cirrhosis status as a function of calendar year per 100000 person-years. Figure presenting total incidence of liver cancer in non-cirrhotic men, men with cirrhosis and in total men, within the calendar years 1969-1973, 1974-1979, 1980-1985, 1986-1991 and 1992-1996 where analogous with Table 3 individuals with prevalent cirrhosis for each 5-year interval were removed.

\section{DISCUSSION}

In the present study, the HR of developing liver cancer among men with cirrhosis compared with men without cirrhosis increased steadily between 1969 and 1996. Recent progress understanding the pathophysiology of cirrhosis and management of the complications of cirrhosis has resulted in reduced mortality rates among persons with end-stage liver disease in the United States (Grattagliano et al, 2011). Thus, it is possible that with improved survival among men with cirrhosis the risk of being diagnosed with other sequel is affected.

The development and overall availability of tools to manage cirrhosis complications has greatly improved in the United States in recent decades, although further improvement is certainly warranted (Kanwal et al, 2011). Since the early 1980s, these tools have included therapeutic options for the prevention of oesophageal varices and recurrent variceal haemorrhage (i.e., drug and endoscopic therapy, transjugular intrahepatic portosystemic shunt); a lower threshold for diagnostic paracentesis in conjunction with earlier detection and treatment of infectious complications; the availability of treatment options for HBV- and HCV-infected patients with compensated cirrhosis; a rising awareness of the importance of renal function monitoring for the earlier diagnosis and management of hepatorenal syndrome; and liver transplantation (Hoefs and Runyon, 1985; Groszmann et al, 1990; Sabba et al, 1990; The Veterans Affairs Cooperative Variceal Sclerotherapy Group, 1991; Poynard et al, 1991; Rossle et al, 1997; Sharara and Rockey, 2001). The use of these and other options have almost certainly had an effect on cirrhosis mortality rates. Whether therapy of cirrhosis inadvertently leads to increases in the risk of liver cancer is not clear, although previous studies suggest that the risk of liver cancer increases linearly from the time of first diagnosis of cirrhosis. In addition, a recent report of an $\mathrm{HCV}$-infected cohort in the VA system found that the incidence of HCC rose more dramatically than previously predicted (Kanwal et al, 2011). Although the cohort described by Kanwal et al (2011) was an HCV-infected cohort rather than a cirrhosis cohort, the majority of HCCs develop among persons with cirrhosis, thus supporting the findings of the current study.

Other possible explanations for the increased HR of liver cancer among men with cirrhosis are several. Better diagnostic detection of liver cancer through a wider application of imaging methods, such as ultrasound and CT/MRI, has occurred in the last several decades. Arguably, before the advent of advanced imaging, cirrhosis patients might have died of hepatic decompensation before a nascent liver cancer could be detected. Another possibility is that the aetiology of the underlying cirrhosis may have changed over time. For example, if the proportion of viral-related cirrhosis and alcohol-related cirrhosis varied, the risk of developing liver cancer might appear to vary also, as viral-related cirrhosis has been reported to carry a higher risk than alcohol-related cirrhosis (Morgan et al, 2004; Bialecki and Di Bisceglie, 2005; Kanwal et al, 2011). Prior reports have suggested that the risk of liver cancer among persons with $\mathrm{HBV}$-related cirrhosis is $\sim 2-3 \%$, whereas the comparable risks for HCV-related and alcohol-related cirrhosis are $1-7 \%$ and $1 \%$, respectively (Morgan et al, 2004; Bialecki and Di Bisceglie, 2005). Consistent with these reports are the findings of the current study. Although the risk of liver cancer varied by type of cirrhosis, however, the HR of liver cancer associated with each type of cirrhosis was increased compared to no cirrhosis, suggesting that a shift in underlying aetiology does not completely account for the increased HRs over time.

Another possible explanation for increasing risk of liver cancer would be better screening for liver cancer over time. There is scant evidence, however, that screening for liver cancer in the United States has improved. For example, a recent report revealed that $<20 \%$ of US patients with cirrhosis who later developed liver cancer received regular screening in the 1990s (Davila et al, 2010).

In the current analysis, HRs of liver cancer were notably higher in white men than black men with most types of cirrhosis, with the exception of viral-related cirrhosis. This racial difference in liver cancer risk is not fully understood, but previous studies have noted that health care and survival trends vary by race, ethnic group and socioeconomic status (Artinyan et al, 2010). In regard to liver cancer, it has been reported that black persons are diagnosed at more advanced stages and experience a poorer survival than white persons (Davila and El-Serag, 2006). Our findings may suggest that white men with cirrhosis also receive better treatment, or treatment at an earlier stage of cirrhosis, and therefore are more likely to survive long enough to develop liver cancer. Mortality rates of cirrhosis support this suggestion. Between 1970 and 2006, the mortality rate of cirrhosis per 100000 persons declined from 16.6 to 7.0 among white persons and from 28.1 to 9.1 among black persons. Although black persons experienced a greater percentage decline in cirrhosis mortality, rates among black persons have remained steadily higher than rates among white persons.

This investigation had a number of strengths, including a very large size of $\sim 4.5$ million persons with 26 million associated records. The study also had a long period of follow-up of almost three decades, which enabled a sufficient number of cancer outcomes to develop at different periods of follow-up. Clinical diagnoses were obtained from medical records and thus were not subject to recall bias. In addition, because minority populations tend to be overrepresented in the VA population, the study was large enough to examine the HRs separately in white and black men (Ashton et al, 1998). Within this study population, the potential for confounding by socioeconomic status may be limited because patients within the VA system are more likely to be similar socioeconomically, than are persons who do not use the VA system (Randall et al, 1987). In addition, previous VA studies have shown similar health care utilisation and outcomes for black and white people (Deswal et al, 2004; Giordano et al, 2006).

Despite its notable strengths, the study also had some limitations. Persons who use the VA health care system are not restricted from using other health care systems. For example, as the VA system does not have many emergency rooms, VA patients who require acute care, might not present at a VA hospital. It is likely, however, that persons with chronic conditions, such as cirrhosis, would continue their care at the VA as the care would be 
given without charge. Similarly, if an individual reported to an emergency room owing to their cancer, they would likely be referred back to the VA system. The current study was restricted to black and white males as there were too few females and nonwhite/non-black males to include. This study was also limited by little information on relevant covariates, such as cigarette smoking, alcohol consumption, diet, physical activity, and body mass. The use of medical conditions as proxy variables, such as COPD for smoking, cannot guarantee that the covariate effect is captured entirely. As such, adjustments for lifestyle variables were likely incomplete. Surrogate variables tend to be conservative estimates of true variables, and thus would be likely to underestimate the association rather than overestimate it. Other covariates, such as obesity, are almost certainly under ascertained in the data, as medical records have much more complete information on conditions that are under treatment rather than conditions that are simply present. The ascertainment of infection with HBV and/ or HCV was also incomplete. Blood tests to detect chronic infection with HBV were not available until the early 1970s, whereas tests for HCV were not available until the early 1990s. Other clinical data, laboratory data, and medical records were not available to verify diagnoses, diagnostic tests or treatment.

Finally, our study included only hospitalised veterans; persons who utilise the VA medical system have been reported to be of lower socioeconomic status and in poorer health compared with the general population (Agha et al, 2000), suggesting that caution should be exercised when extrapolating results to the general population.

In conclusion, the current study shows that the hazard of developing liver cancer among men with cirrhosis in the VA health care system significantly increased between 1969 and 1996. Although the increased hazard is compatible with numerous explanations, it is possible that better treatment of cirrhosis has resulted in higher hazards of liver cancer diagnoses over time. Further study of this question in other populations is warranted.

\section{ACKNOWLEDGEMENTS}

We thank the Medical Administration Service of the US Veterans Health Services and Research Administration for providing the data on which this study is based, and Eric Boyd and Dave S Campbell of Information Management Services Inc. for programming support. This research was supported by the Intramural Research Program of the National Cancer Institute, National Institutes of Health, Department of Health and Human Services.

\section{Conflict of interest}

The authors declare no conflict of interest.

\section{REFERENCES}

Agha Z, Lofgren RP, VanRuiswyk JV, Layde PM (2000) Are patients at veterans affairs medical centers sicker? A comparative analysis of health status and medical resource use. Arch Intern Med 160(21): 3252-3257

Altekruse SF, McGlynn KA, Reichman ME (2009) Hepatocellular carcinoma incidence, mortality, and survival trends in the United States from 1975 to 2005. J Clin Oncol 27(9): 1485-1491

Artinyan A, Mailey B, Sanchez-Luege N, Khalili J, Sun CL, Bhatia S, Wagman LD, Nissen N, Colquhoun SD, Kim J (2010) Race, ethnicity, and socioeconomic status influence the survival of patients with hepatocellular carcinoma in the United States. Cancer 116(5): 1367-1377

Ashton CM, Petersen NJ, Wray NP, Yu HJ (1998) The Veterans Affairs medical care system: hospital and clinic utilization statistics for 1994. Med Care 36(6): 793-803

Bialecki ES, Di Bisceglie AM (2005) Clinical presentation and natural course of hepatocellular carcinoma. Eur J Gastroenterol Hepatol 17(5): 485-489

Bosetti C, Levi F, Lucchini F, Zatonski WA, Negri E, La VC (2007) Worldwide mortality from cirrhosis: an update to 2002. J Hepatol 46(5): 827-839

Davila JA, El-Serag HB (2006) Racial differences in survival of hepatocellular carcinoma in the United States: a population-based study. Clin Gastroenterol Hepatol 4(1): 104-110

Davila JA, Henderson L, Kramer JR, Kanwal F, Richardson PA, Duan Z, El-Serag HB (2011) Utilization of surveillance for hepatocellular carcinoma among hepatitis $C$ virus-infected veterans in the United States. Ann Intern Med 154(2): 85-93

Davila JA, Morgan RO, Richardson PA, Du XL, McGlynn KA, El-Serag HB (2010) Use of surveillance for hepatocellular carcinoma among patients with cirrhosis in the United States. Hepatology 52(1): 132-141

Davila JA, Morgan RO, Shaib Y, McGlynn KA, El-Serag HB (2004) Hepatitis $\mathrm{C}$ infection and the increasing incidence of hepatocellular carcinoma: a population-based study. Gastroenterology 127(5): 1372-1380

Deswal A, Petersen NJ, Souchek J, Ashton CM, Wray NP (2004) Impact of race on health care utilization and outcomes in veterans with congestive heart failure. J Am Coll Cardiol 43(5): 778-784

El-Serag HB, Tran T, Everhart JE (2004) Diabetes increases the risk of chronic liver disease and hepatocellular carcinoma. Gastroenterology 126(2): 460-468

Giordano TP, Morgan RO, Kramer JR, Hartman C, Richardson P, White Jr. CA, Suarez-Almazor ME, El-Serag HB (2006) Is there a race-based disparity in the survival of veterans with HIV? J Gen Intern Med 21(6): 613-617
Grattagliano I, Ubaldi E, Bonfrate L, Portincasa P (2011) Management of liver cirrhosis between primary care and specialists. World J Gastroenterol 17(18): 2273-2282

Groszmann RJ, Bosch J, Grace ND, Conn HO, Garcia-Tsao G, Navasa M, Alberts J, Rodes J, Fischer R, Bermann M (1990) Hemodynamic events in a prospective randomized trial of propranolol versus placebo in the prevention of a first variceal hemorrhage. Gastroenterology 99(5): 1401-1407

Hoefs JC, Runyon BA (1985) Spontaneous bacterial peritonitis. Dis Mon 31(9): 1-48

Kanwal F, Hoang T, Kramer JR, Asch SM, Goetz MB, Zeringue A, Richardson P, El-Serag HB (2011) Increasing prevalence of HCC and cirrhosis in patients with chronic hepatitis C virus infection. Gastroenterology 140(4): 1182-1188

Morgan TR, Mandayam S, Jamal MM (2004) Alcohol and hepatocellular carcinoma. Gastroenterology 127(5 Suppl 1): S87-S96

National Center for Health Statistics (US). Health, United States (2009) With Special Feature on Medical Technology. 2010-1232. 2010. National Center for Health Statistics (US): Hyattsville (MD)

Neuschwander-Tetri BA, Caldwell SH (2003) Nonalcoholic steatohepatitis: summary of an AASLD Single Topic Conference. Hepatology 37(5): 1202-1219

Page WF, Mahan CM, Kang HK (1996) Vital status ascertainment through the files of the Department of Veterans Affairs and the Social Security Administration. Ann Epidemiol 6(2): 102-109

Poynard T, Cales P, Pasta L, Ideo G, Pascal JP, Pagliaro L, Lebrec D (1991) Beta-adrenergic-antagonist drugs in the prevention of gastrointestinal bleeding in patients with cirrhosis and esophageal varices. An analysis of data and prognostic factors in 589 patients from four randomized clinical trials. Franco-Italian Multicenter Study Group. $N$ Engl J Med 324(22): 1532-1538

Randall M, Kilpatrick KE, Pendergast JF, Jones KR, Vogel WB (1987) Differences in patient characteristics between veterans administration and community hospitals. Implications for VA planning. Med Care 25(11): 1099-1104

Rossle M, Deibert P, Haag K, Ochs A, Olschewski M, Siegerstetter V, Hauenstein KH, Geiger R, Stiepak C, Keller W, Blum HE (1997) Randomised trial of transjugular-intrahepatic-portosystemic shunt versus endoscopy plus propranolol for prevention of variceal rebleeding. Lancet 349(9058): 1043-1049

Sabba C, Weltin GG, Cicchetti DV, Ferraioli G, Taylor KJ, Nakamura T, Moriyasu F, Groszmann RJ (1990) Observer variability in echo-Doppler measurements of portal flow in cirrhotic patients and normal volunteers. Gastroenterology 98(6): 1603-1611 
Schutte K, Bornschein J, Malfertheiner P (2009) Hepatocellular carcinomaepidemiological trends and risk factors. Dig Dis 27(2): 80-92

Sharara AI, Rockey DC (2001) Gastroesophageal variceal hemorrhage. $N$ Engl J Med 345(9): 669-681

The Veterans Affairs Cooperative Variceal Sclerotherapy Group (1991) Prophylactic sclerotherapy for esophageal varices in men with alcoholic liver disease. A randomized, single-blind, multicenter clinical trial. $N$ Engl J Med 324(25): 1779-1784

Welzel TM, Graubard BI, Zeuzem S, El-Serag HB, Davila JA, McGlynn KA (2011) Metabolic syndrome increases the risk of primary liver cancer in the United States: A population-based case-control study. Hepatology 54(2): 463-471

This work is published under the standard license to publish agreement. After 12 months the work will become freely available and the license terms will switch to a Creative Commons Attribution-NonCommercial-Share Alike 3.0 Unported License. 